\title{
Development of Technical Requirements for On- Board Cryogenic Fuel Systems of Belaz Dump Trucks
}

\author{
Georgiy Dubov ${ }^{1 *}$, Dmitriy Trukhmanov ${ }^{1}$, Sergey Nokhrin $^{2}$ and Aleksey Sergel ${ }^{3}$ \\ ${ }^{1}$ T.F. Gorbachev Kuzbass State Technical University, Department of Mechanical Engineering Tech- \\ nology, 28 Vesennya st., Kemerovo, the Russian Federation \\ ${ }^{2} \mathrm{OOO} «$ Sibir-Energo», 13 Schyorsa st., Novokuznetsk, the Russian Federation \\ ${ }^{3} \mathrm{OAO}$ «BELAZ» - Management Company of Holding «BELAZ-HOLDING», 440 let Octyabrya st., \\ Zhodino, Minsk region, Republic of Belarus
}

\begin{abstract}
The state-of-the-art of the issue of the efficiency and relevance of the use of liquefied natural gas (LNG) as a motor fuel in the operation of dump trucks is considered. An analysis of the benefits of using LNG as a motor fuel is given. It is noted that, LNG seems to be the most promising alternative to oil types of motor fuel in the segment of open-pit truck haulage. It is affirmed that in Russia, in Kuzbass, the group of companies successfully implemented for the first time an integrated project for the production of LNG and its consumption in relation to BelAZ dump trucks. Data on the relevance and the need to develop technical requirements for on-board cryogenic fuel systems of mine dump trucks are given. Data on the developed groups of technical requirements for on-board cryogenic fuel systems of BelAZ dump trucks are given. It is said that the developed technical requirements made it possible to solve a number of tasks related to the development of circuit and design solutions for equipping BelAZ dump trucks with cryogenic systems. It is argued that the developed technical requirements will contribute to the further development of domestic projects for the production and consumption of liquefied natural gas.
\end{abstract}

\section{Introduction}

Eco-economic efficiency of open-pit mining directly depends on the type of haulage vehicles used. The main type of vehicle for rock mass hauling is a heavy-duty mine dump truck. The share of hauling operations can be up to $40-50 \%$ in the total cost of mining. Thus, one of the main components of the cost of one ton of diggings is the cost of diesel fuel [1].

A universal indicator of the efficiency of mine dump trucks is the energy intensity of rock mass hauling process. When assessing the energy intensity of rock mass hauling process, the specific energy consumption is taken as the unit of measurement of the energy intensity. Earlier studies show that the energy intensity of rock mass hauling by gas-dieselfuelled mine dump trucks (when diesel fuel is partly replaced with liquefied natural gas methane) is less than that of diesel-powered mine trucks [2].

\footnotetext{
*Corresponding author: nikokem@mail.ru
} 
Partial replacement of diesel with liquefied natural gas - methane - provides a number of technical advantages in the operation of mine truck fleet [1, 3-6]:

- conversion of trucks to partial diesel fuel replacement with liquefied natural gas does not require significant design conversion of an engine;

- engine power does not change;

- engine life becomes longer;

- diesel fuel consumption is reduced;

- overall haulage and operational costs are reduced;

- engine noise is reduced.

Currently, researches are conducted, and a number of innovative projects related to the conversion of mine dump trucks to alternative sources of fuel are implemented. The projects related to the conversion of haulage trucks to dual (gas-diesel) fuel operation using liquefied natural gas as a motor fuel are the most widespread. This is due to the fact that liquefied natural gas seems to be the most promising alternative to petroleum-based motor fuels, as evidenced by several studies in this area [7-13].

It is also necessary to note the current relevance of the implementation of this kind of projects, confirmed by the latest instructions of the President to the Government of the Russian Federation regarding the development of projects for the liquefied gas production and the increase of the use of gas as a motor fuel.

In the program of development of coal industry in Russia, it is planned to increase coal production to 500 million tons per year by 2030 . This, in the near future, will encourage mining companies to use open-pit mining equipment with higher rates of environmental and economic efficiency at their production sites [14].

The aim of this work is to develop a list of the basic technical requirements for on-board cryogenic fuel systems installed on BelAZ dump trucks, and ensure the possibility of their dual-fuel (gas-diesel) operation using liquefied natural gas - methane.

\section{Results and Discussion}

It is known that heavy-duty mine trucks consume a large amount of diesel fuel. For example, a 130-ton BelAZ dump truck consumes about two tons of diesel fuel per day. The use of LNG as a motor fuel, and especially for heavy-duty mine dump trucks, has a number of significant advantages. The key ones are: profitability - directly related to the fact that the cost of liquefied natural gas is lower than that of the volume of diesel fuel equivalent in calorific value. Environmental friendliness - expressed in reducing gas pollution at production sites and reducing the amount of toxic, carcinogenic substances and solid particles released into the atmosphere (emissions of nitrogen oxides, carbon monoxide, hydrocarbons are reduced, emissions of lead compounds, sulfur and soot are minimized). The safety of rock mass hauling process increases due to the fact that the auto-ignition temperature of natural gas is much higher than that of diesel fuel (diesel fuel: $315^{\circ} \mathrm{C}$; methane: $540^{\circ} \mathrm{C}$ ).

Today, in Kuzbass, and in Russia as a whole, the first integrated project for the production of LNG and the conversion of heavy-duty BelAZ dump trucks to gas-diesel operation has been successfully implemented by the group of companies of the limited liability company "Resurs" - LLC "Siber-Energo" and LLC "TehnoEko".

In the course of the project implementation in 2017, "Siber-Energo" put into operation the first production line of liquefied natural gas plant with a production capacity of 1.5 tons per hour (Fig. 1). A refueling infrastructure is created, including modern, unparalleled in the Russian Federation cryogenic mobile refuellers and refueling sites directly at mining sites (Fig. 2). As of June 2019, more than 50 BelAZ 75131 dump trucks (with loading ca- 
pacity of 130 tons) are equipped with on-board cryogenic fuel systems and are successfully operated (Fig. 3).

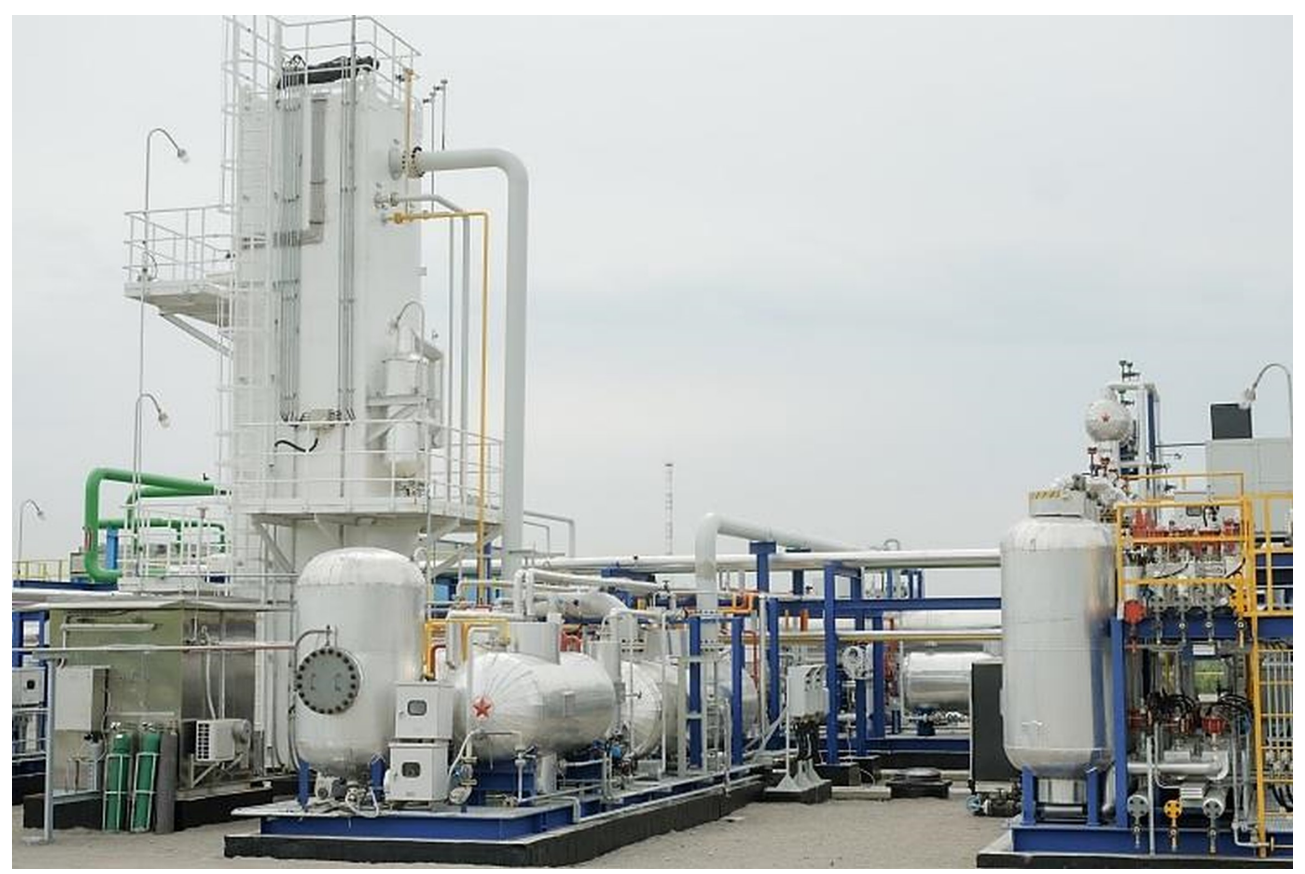

Fig. 1. Liquefied natural gas plant (Russia, Novokuznetsk, LLC "Sibir-Energo")

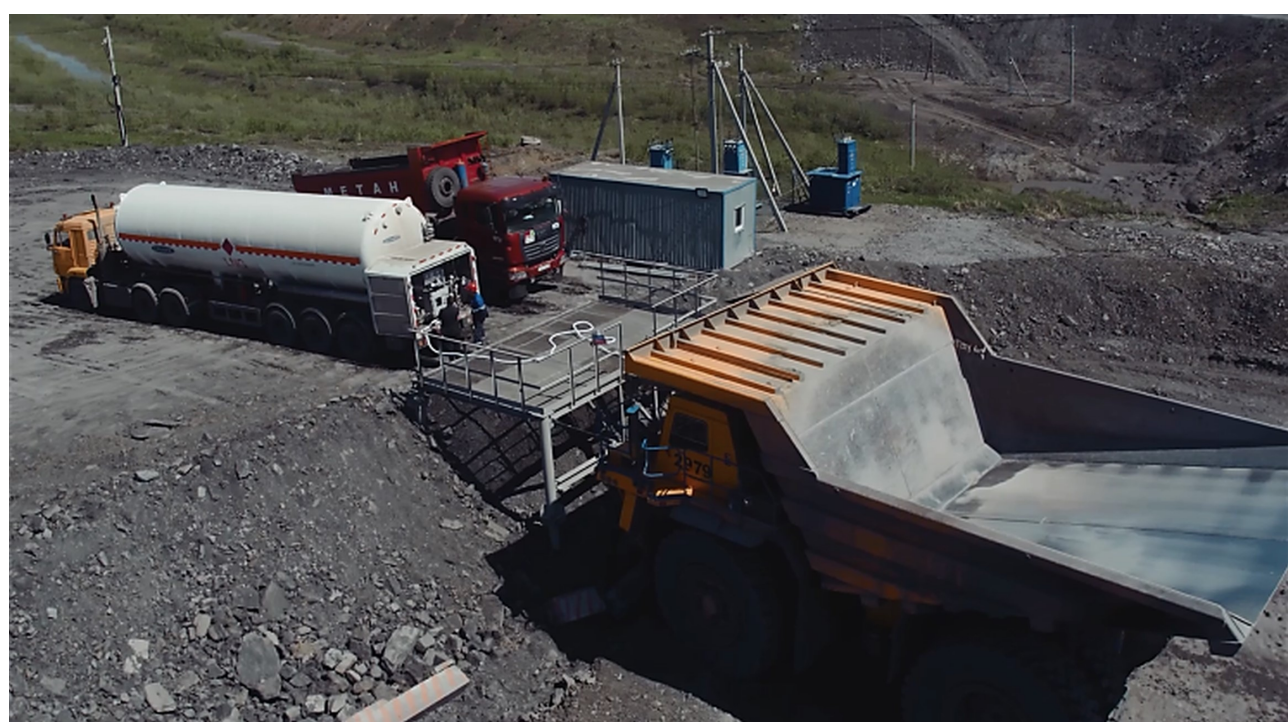

Fig. 2. Stationary platform for refueling dump trucks with liquefied natural gas 


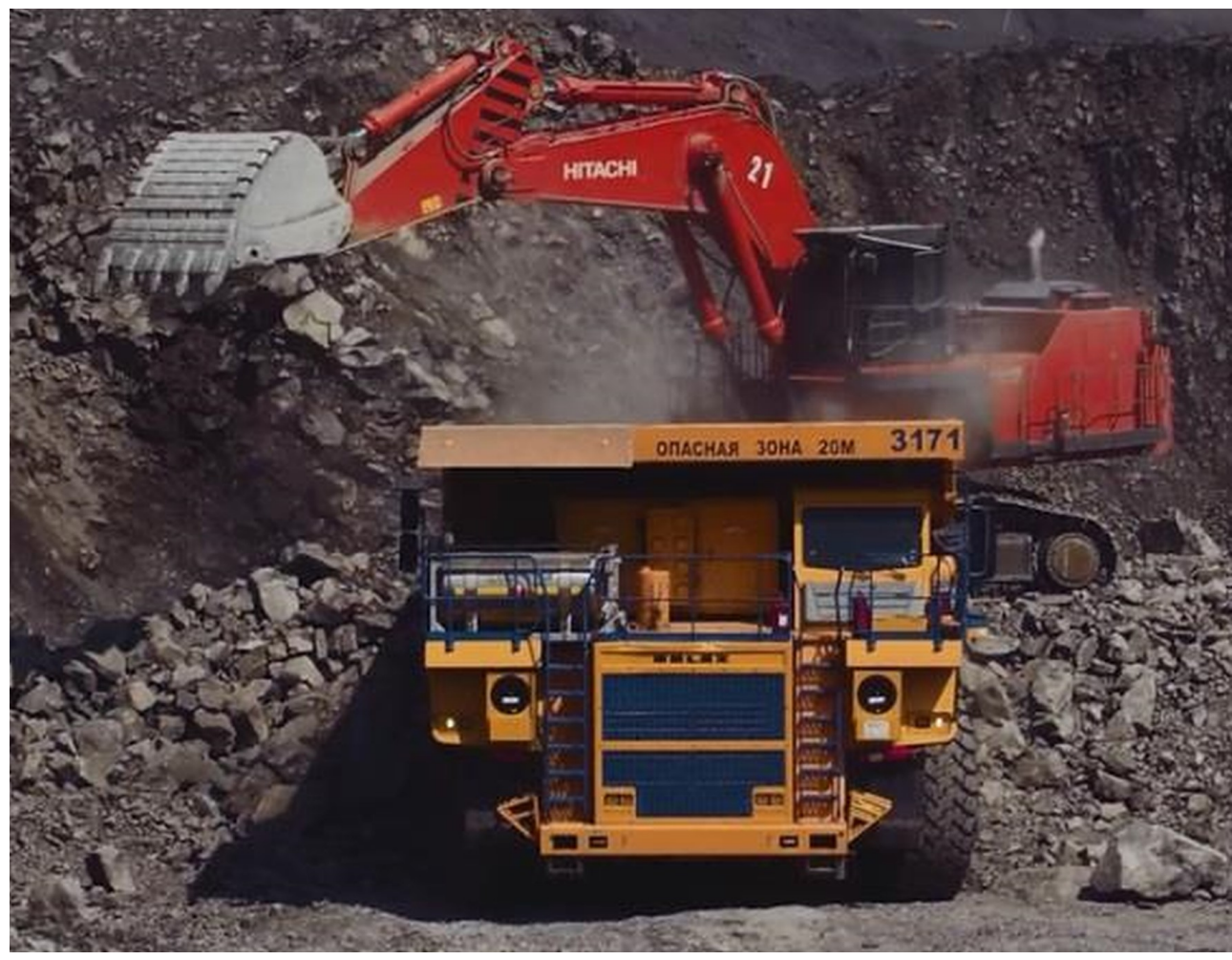

Fig. 3. BelAZ 75131 mine dump truck equipped with an on-board cryogenic fuel system

Currently, there are two national standards in Russia regulating the operation of motor vehicles equipped with on-board cryogenic fuel systems allowing their operation on liquefied natural gas. These include:

1. GOST P 56217-2014 Motor vehicles using gas as a motor fuel. General technical requirements for the operation on liquefied natural gas, safety regulations and test methods.

This standard establishes the technical requirements for the operation of on-board cryogenic fuel systems installed on motor vehicles running on liquefied natural gas.

2. GOST P 56218-2014 Motor vehicles running on liquefied natural gas. Cryogenic power systems. Technical requirements and test methods.

This standard establishes the technical requirements for an on-board cryogenic fuel system for motor vehicles and its test methods.

The above national standards regulate the technical requirements for the operation of on-board cryogenic fuel systems, as well as the systems installed on motor vehicles of categories M and N. In accordance with GOST P 52051-2003, category M includes motor vehicles with at least four wheels and used to carry passengers; category $\mathrm{N}$ includes motor vehicles with at least four wheels and intended for cargo carriage. BelAZ dump trucks cannot be fully attributed to any of the above categories of vehicles for a number of objective reasons related to the characteristics of their design and operating conditions.

Considering the above, it becomes obvious that the existing national standards for onboard cryogenic fuel systems cannot be fully applied to mine vehicles, including BelAZ dump trucks. This circumstance led to the need to develop new technical requirements for on-board cryogenic fuel systems of mine dump trucks.

The developed list of the main groups of technical requirements for on-board cryogenic fuel systems (OCFS) of BelAZ dump trucks is presented in Fig. four. 


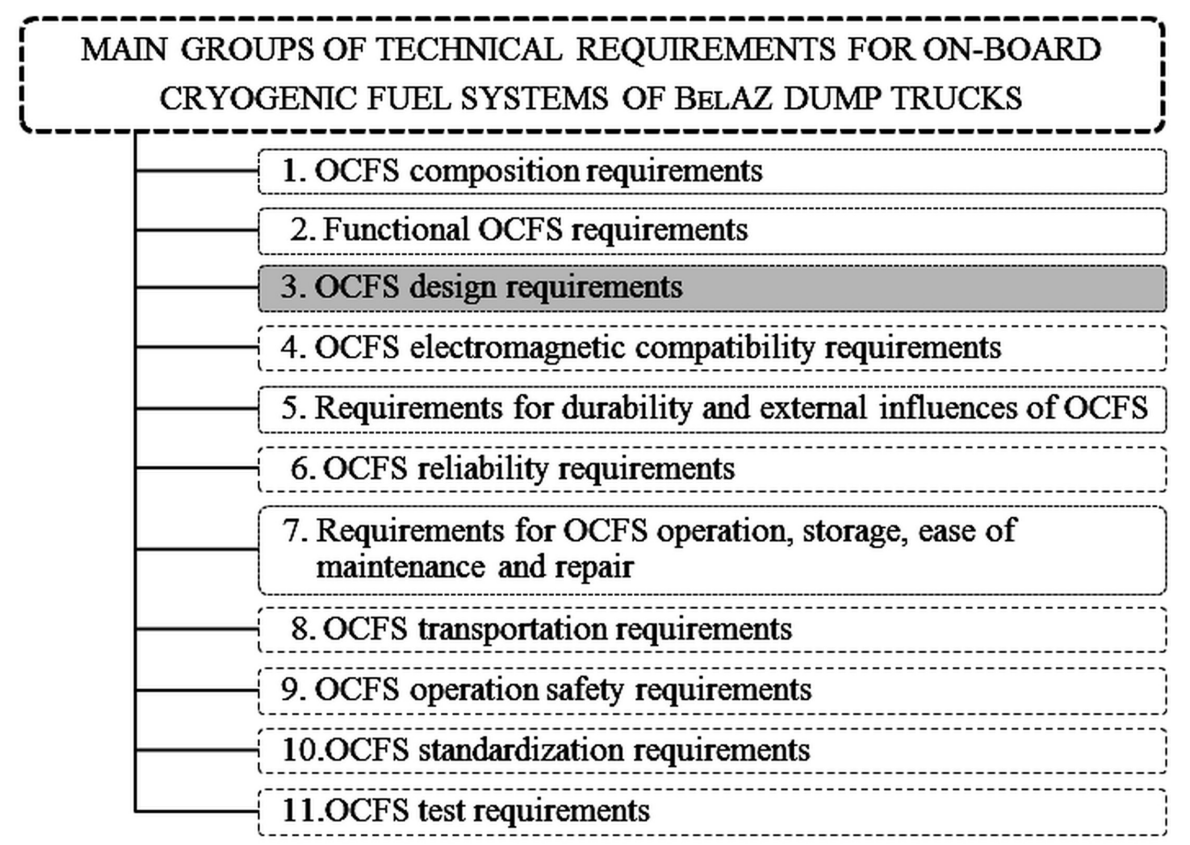

Fig. 4. The list of the main groups of technical requirements for on-board cryogenic fuel systems of BelAZ dump trucks

Each of the above groups of main technical requirements includes necessary and mandatory subgroups of requirements. As an example, the list of subgroups included in the third main group of technical requirements for on-board cryogenic fuel systems of BelAZ dump trucks is shown in Fig. 5. 


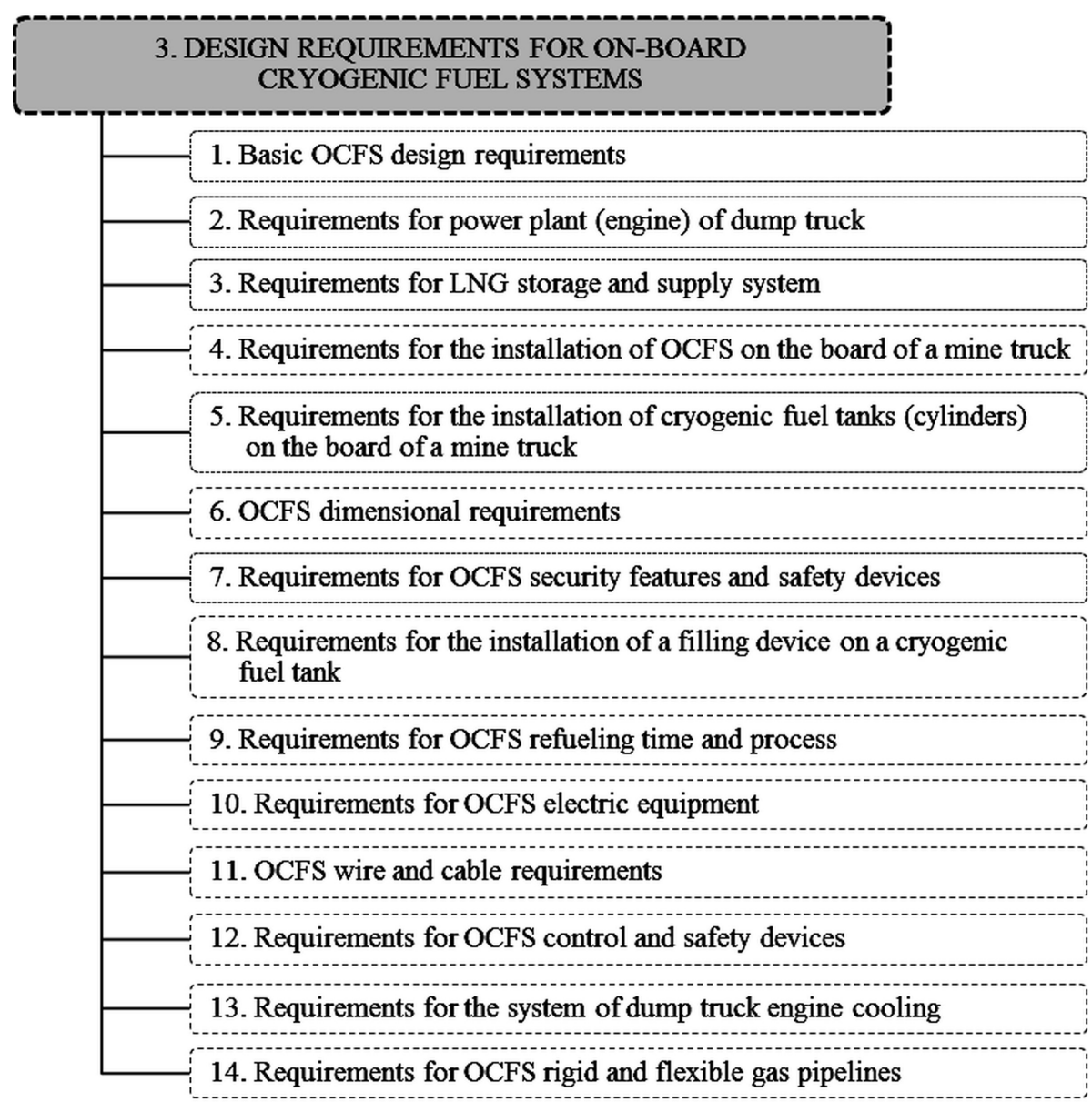

Fig. 5. The list of subgroups of technical requirements included in the main group of technical requirements: "design requirements for on-board cryogenic fuel systems".

The above technical requirements for on-board cryogenic fuel systems of BelAZ dump trucks were developed taking into account their operation in the conditions of Siberia and the Far North. This is an important indicator, since the main mining companies of Russia operate in these regions, and the most BelAZ dump trucks are operated there.

In addition to the technical requirements for on-board cryogenic fuel systems of BelAZ dump trucks presented in Figure 4 and Figure 5, additional groups of requirements were developed. The need to develop additional requirements is regulated by existing State standards for new types of equipment and technologies. These include:

- requirements for raw materials, materials and components included in the on-board cryogenic fuel system package;

- requirements for conservation, packaging and labeling of on-board cryogenic fuel systems;

- requirements for documentation and certification of on-board cryogenic fuel systems.

The relevance and the need to develop technical requirements are also confirmed by the fact that BelAZ mining dump truck is intended for rock mass hauling in complex mining and technical conditions of deep open-pits along haul road in various climatic operation conditions (at ambient temperature from $-50^{\circ} \mathrm{C}$ to $+50^{\circ} \mathrm{C}$ ). 
In addition, the development of circuit and design solutions for the conversion of BelAZ dump trucks to dual-fuel (gas-diesel) operation also required the development of technical requirements for on-board cryogenic fuel systems at the initial stage.

The developed technical requirements allowed solving a number of the following new tasks then, namely:

- to develop circuit and design solutions for equipping BelAZ 75131 mine dump trucks with on-board cryogenic fuel systems;

- to develop a technical project for the conversion of BelAZ 75131 dump truck to dual-fuel (gas-diesel) operation;

- to develop and manufacture prototypes of on-board cryogenic fuel systems for BelAZ 75131 dump truck;

- to conduct industrial tests of prototypes of on-board cryogenic fuel systems to determine the possibility of their further serial installation on BelAZ 75131 mine dump trucks;

- to develop a set of standards and operational documentation for on-board cryogenic fuel system of BelAZ 75131 mine dump truck (passport, installation and operation manual, etc.).

\section{Conclusion}

Implementation of projects for the production and consumption of liquefied natural gas in Russia is at the initial stage of its formation. The poor development of own large-capacity gas liquefaction technologies in Russia, engineering standard and operational documentation for on-board cryogenic fuel equipment, makes Russian projects dependent on foreign suppliers of technology, equipment and services. The first developed technical requirements for on-board cryogenic fuel systems of BelAZ dump trucks will give further impetus to the development and implementation of domestic projects for the production and consumption of liquefied natural gas in relation to open-pit truck haulage.

\section{References}

1. M.L. Khazin, PJPME, 19:1, 56 (2019)

2. I.V. Kuznetsov, I.A. Panachev, G.M. Dubov, S.A. Nohrin, Handbook. An Engineering journal, 4, 19 (2019)

3. J. Osorio-Tejada, E. Llera, S. Scarpellini, WIT Transactions on The Built Environment, 168, 235 (2015)

4. V.Y. Koptev, A.V. Kopteva, IOP Conf. Ser.: Earth Environ. Sci., 87:2, 022010 (2017)

5. K. Cheenkachorn, C. Poompipatpong, C.G. Ho, Energy, 53, 52 (2013)

6. H.A.A. Wahhab, M.A. Ismael, A. Aziz, M.R. Heikal, AJAS, 10:2, 88 (2017)

7. G.M. Dubov, D.S. Trukhmanov, I.V. Kuznetsov, S.A. Nokhrin, A.N. Sergel, E3S Web Conf., 105, 03018 (2019)

8. G.M. Dubov, D.S. Trukhmanov, I.V. Kuznetsov, S.A. Nokhrin, A.N. Sergel, E3S Web Conf., 105, 03019 (2019)

9. A.G. Goncharuk, V.I. Havrysh, V.S. Nitsenko, IJETP, 14:2-3, 226 (2018).

10. A. Thiruvengadam, M. Besch, D. Carder, A. Oshinuga, JA\&WMA, 66:11, 1045 (2016)

11. D.C. Quiros, J. Smith, A. Thiruvengadam, T. Huai, Atmospheric Environ., 168, 36 (2017)

12. A.S. Ivanov, I.A. Anisimov, E.M. Chikishev, Autogas Filling Complex + Alternative Fuel, 12:81, 17 (2013)

13. N. Dronniou, J. Kashdan, B. Lecointe, K. Sauve, D. Soleri, SAE International Journal of Engines, 7:2, 873 (2014)

14. G.M. Dubov, D.S. Trukhmanov, A.A. Chegoshev, V.E. Ashikhmin, E3S Web Conf., 41, 03008 (2018) 